\title{
Entrepreneurial orientation, competitive advantage, and SMEs' performance: application of firm growth and personal wealth measures
}

\author{
Kibeshi Kiyabo* ${ }^{*}$ and Nsubili Isaga
}

* Correspondence: kikiyabo15@ mustudent.ac.tz

School of Business, Mzumbe University, P. O. Box 6 Mzumbe, Morogoro, Tanzania

\begin{abstract}
SMEs' performance can be measured using various indicators. Guided by the resourcebased view, this study aimed at determining the influence of entrepreneurial orientation on SMEs' performance under the mediation of competitive advantage using firm growth and personal wealth measures. Entrepreneurial orientation was adopted as an intangible resource in form of processes. A survey method with cross-sectional design was used to collect data from 300 owners-managers of welding industry SMEs located in Dar es Salaam, Mbeya, and Morogoro urban centers in Tanzania. By the aid of AMOS software, data analysis comprised of developing measurement and structural models using structural equation modeling technique. Sample data were then bootstrapped using 200 samples to determine the indirect effect of entrepreneurial orientation on SMEs' performance through competitive advantage. Findings from this study inform that competitive advantage mediates the relationship between entrepreneurial orientation and SMEs' performance for both firm growth and personal wealth performance measures. This study has contributed to existing literature by providing evidence on use of personal wealth as measures of SMEs' performance. The findings of the study imply that the resource-based view is suitable in describing not only physical resources but also intangible resources such as entrepreneurial orientation. Future studies may investigate the influence of more constructs such as learning orientation on SMEs' performance under the mediation of competitive advantage using the same firm growth and personal wealth performance measures. Such studies will establish whether the findings of this study are specific to entrepreneurial orientation construct or applicable to other constructs as well.
\end{abstract}

Keywords: Competitive advantage, Entrepreneurial orientation, Firm growth, Personal wealth, SMEs' performance

\section{Introduction}

SMEs' performance refers to the outcomes of firms' business activities (Kotane \& Kuzimina-Merlino, 2017). It can be measured using various indicators. Firm growth indicators are among important SMEs' performance measures. Shepherd and Wiklund (2009)

(c) The Author(s). 2020 Open Access This article is licensed under a Creative Commons Attribution 4.0 International License, which permits use, sharing, adaptation, distribution and reproduction in any medium or format, as long as you give appropriate credit to the original author(s) and the source, provide a link to the Creative Commons licence, and indicate if changes were made. The images or other third party material in this article are included in the article's Creative Commons licence, unless indicated otherwise in a credit line to the material. If material is not included in the article's Creative Commons licence and your intended use is not permitted by statutory regulation or exceeds the permitted use, you will need to obtain permission directly from the copyright holder. To view a copy of this licence, visit http://creativecommons.org/licenses/by/4.0/. 
identified five common firm growth measures that have been used in past studies; these are growth in sales, employees, profit, assets, and equity. There is no doubt that SMEs' performance measures have been developed in western countries. Entrepreneurs in western world are motivated by availability of opportunities to be exploited while entrepreneurs in least developed countries are motivated by necessities (Eijdenberg, 2016). While earnings from entrepreneurial businesses in western countries can solely be used to foster firm growth, part of earnings from least developed countries go to personal expenses to support the lives of the entrepreneurs. This reality has raised a need to measure SMEs' performance using personal wealth indicators as suggested in Eijdenberg (2016). Since use of personal wealth to measure SMEs' performance in least developed countries like Tanzania is a new approach, it is not yet known whether entrepreneurial orientation influences such measures (Eijdenberg, 2016).

The current study simultaneously investigated the influence of entrepreneurial orientation on SMEs' performance under the mediation of competitive advantage using the conventional firm growth and novel personal wealth measures. Therefore, the study used assets, sales, and number of employees as measures of firm growth (Shepherd \& Wiklund, 2009). Food purchasing, health care paying, and shelter acquisition capabilities were used as personal wealth performance measures (Eijdenberg, 2016). The use of the two types of performance measures was employed to foster comparison of research results to obtain empirical evidence so as to ascertain the extent the personal wealth measures are closer or far away from traditional firm growth performance measures.

Therefore, the main objective of this study was to determine the influence of entrepreneurial orientation on SMEs' performance under the mediation of competitive advantage using firm growth and personal wealth SMEs' performance measures. Specifically, the study aimed at determining the (1) influence of entrepreneurial orientation on competitive advantage, (2) influence of competitive advantage on SMEs' performance, and (3) mediating effect of competitive advantage on the relationship between entrepreneurial orientation and SMEs' performance.

In accomplishing the main and specific objectives, the study adopted a quantitative research paradigm with cross-sectional design to collect data from owners-managers of welding industry SMEs in urban centers of Dar es Salaam, Mbeya, and Morogoro in Tanzania. The study used five dimensions of entrepreneurial orientation construct as adopted from Campos, Nuno de la Parra, and Parellada (2012) and three dimensions of competitive advantage as adopted from Ramaswami, Srivastava, and Bhargava (2006). Furthermore, the study used three performance measures for firm growth as adopted from Shepherd and Wiklund (2009) and three performance measures for personal wealth as adopted from Eijdenberg (2016).

\section{Literature review}

Entrepreneurial orientation refers to "processes, practices, and decision-making activities that lead to new entry" (Lumpkin \& Dess, 1996, p.136). A firm is said to enter new entry when it introduces new products, services, technological innovations, markets, or business model innovations that did not exist before (Covin, Wales, \& J., 2019). Earlier studies measured entrepreneurial orientation construct using three dimensions, namely, innovativeness, pro-activeness, and risk taking (Miller, 1983 cited in Zulkifli \& Rosli, 2013). 
Later, two more dimensions were introduced to measure entrepreneurial orientation; these are autonomy and competitive aggressiveness (Lumpkin \& Dess, 1996). A keen look on literature reveals that researchers have been using both measures, for example, Amin (2015), Amin, Thurasamy, Mohamad, Aznur, and Kaswuri (2016), Chenuos and Maru (2015), and Mahmood and Hanafi (2013) used three dimensions to measure entrepreneurial construct. Other researchers such as Campos and Valenzuela (2013), Zehir, Can, and Karaboga (2015), and Zulkifli and Rosli (2013) used five dimensions to measure the construct.

Entrepreneurial orientation has actually emerged as one of the most studied construct in entrepreneurship and management literature for more than three decades ago (Covin et al., 2019; Gupta, 2015). Despite the presence of many articles studying entrepreneurial orientation in top entrepreneurship and related journals, literature is in deficit of high value added entrepreneurial orientation research domains (Covin et al., 2019). Most studies have used entrepreneurial orientation as an independent variable while firm performance has been used as a dependent variable; this frequently studied relationship has led to replications with little consideration to identification and assessment of mechanisms and mediating variables through which firm performance occurs (Covin et al., 2019).

Although there exists a number of mediators between entrepreneurial orientation and firm performance, this study anticipates that competitive advantage is likely to mediate the relationship. This mediation is supported by the resource-based view which suggests that a firm's competitive advantage and superior performance emanate from the firm-specific resources and capabilities that are costly for copying by rivals, valuable, rare, imperfectly imitable, and non-substitutable (Barney, 1991). Furthermore, Barney (1991) reiterates that resources include but not limited to assets, capabilities, organizational processes, firm attributes, information, and knowledge. Since entrepreneurial orientation refers to among others the processes that lead to new entry (Lumpkin \& Dess, 1996), this study argues that entrepreneurial orientation is an intangible firm resource that creates competitive advantage and eventually promotes firm performance. Differences in performance among different firms are much driven by intangible rather than physical assets due to the fact that intangible assets unlike physical assets are not vulnerable to imitation (Connor, 2002).

Competitive advantage occurs when a firm implements a value creating strategy that is not concurrently implemented by rivals (Barney, 1991). Despite the importance of competitive advantage as described in the resource-based view, the mediating effect of competitive advantage on the relationship between entrepreneurial orientation and firm performance is not yet extensively studied (Mahmood \& Hanafi, 2013). Competitive advantage can be reflected in several dimensions such as differentiated products, market sensing, collaboration with partners, focus on high value customers, market responsiveness, customers as assets, information transparency, and supply chain leadership (Ramaswami et al., 2006). Competitive advantage is a construct whose measurement is still fragmented, for example, Mahmood and Hanafi (2013) used differentiated products, market sensing, and market responsiveness as dimensions of competitive advantage. In another study by Ismail, Rose, Abdullah, and Uli (2010), competitive advantage was measured using cost-based advantage, product-based advantage, and service-based advantage. Other measurements of competitive advantage include price or cost, quality, 
delivery dependability, product innovation, and time to market (Wijetunge, 2016). These heterogeneous measures of competitive advantage elevate difficulty in knowledge accumulation.

Despite the consensus among scholars that firm performance is a dependent variable in entrepreneurial orientation studies, no generic measures of firm performance are agreed so far. Past studies have been using diverse indicators to measure firm performance. However, financial performance measures have been mostly used as compared to non-financial performance measures. According to Chong (2008), examples of financial performance measures include profit before tax, profit per employee, growth in revenue, and growth in number of employees. Examples of non-financial performance measures are customers' satisfaction, customers' referral rate, growth in customers' base, and market share (Chong, 2008). Use of heterogeneous performance measures is a probable reason for mixed results found in literature (Shepherd \& Wiklund, 2009). In addition to financial and non-financial measures, it has been argued that personal wealth measures can be used in the least developed countries to measure SMEs' performance (Eijdenberg, 2016).

Findings from past studies show that entrepreneurial orientation influences SMEs' performance (Amin, 2015; Amin et al., 2016; Fatoki, 2012; Mahmood \& Hanafi, 2013; Mata \& Aliyu, 2014; Rauch, Wiklund, Lumpkin, \& Frese, 2009; Yeni, 2015; Zehir et al., 2015). These findings are in agreement with the resource-based theory which suggests that a firm's competitive advantage and superior performance emanate from the firmspecific resources and capabilities (Barney, 1991). Despite the importance of competitive advantage in promoting firm performance as suggested in the resource-based view, past studies have not paid much attention in studying its mediating effect on the entrepreneurial orientation-firm performance relationship (Mahmood \& Hanafi, 2013). However, some studies have observed the positive and significant influence of entrepreneurial orientation on competitive advantage (Mustafa, Rehman, Zaidi, \& Iqbal, 2015). In another study, Mahmood and Hanafi (2013) found partial mediation between entrepreneurial orientation and SMEs' performance. Furthermore, past studies have also demonstrated that competitive advantage positively and significantly influences firm performance (e.g., Ismail et al., 2010; Majeed, 2011; Muafi \& Roostika, 2014; Wijetunge, 2016; Zhou, Brown, \& Dev, 2009). From these findings and the postulation of the resource-based view, this study hypothesizes that

$\mathrm{H}_{1}$ : Entrepreneurial orientation positively influences competitive advantage,

$\mathrm{H}_{2}$ : Competitive advantage positively influences SMEs' performance, and

$\mathrm{H}_{3}$ : Competitive advantage mediates the relationship between entrepreneurial orientation and SMEs' performance.

\section{Methodology}

Research design

A survey method with cross-sectional design was used to collect the data from ownersmanagers of welding industry SMEs located in Dar es Salaam, Mbeya, and Morogoro urban centers in Tanzania. Sample size for the study was determined by rule of thumb under the guidance of the requirements for data analysis techniques. A sample size of 120 subjects is considered adequate for factor loadings \pm 0.5 or above (Hair Jr., Black, 
Babin, \& Anderson, 2010). Structural equation modeling requires 15-20 observations for each independent variable or predictor (Hair Jr. et al., 2010).

This study used entrepreneurial orientation construct as a predictor of SMEs' performance and competitive advantage. Furthermore, competitive advantage construct was used as a predictor of SMEs' performance. Entrepreneurial orientation has 14 items and competitive advantage has 12 items. Thus, the highest number of items in the model is 14 . Multiplying 14 by a minimum number of observations (subjects), which is 15 yielded a minimum sample size of 210 subjects. Structural equation modeling technique uses a chi-square statistic to assess model goodness of fit. The statistic is sensitive to high sample sizes, that is the larger the sample size, the high the likelihood the model will fail (Barret, 2007). Thus, the sample size of 100 to 400 subjects is suggested for models that require use of structural equation modeling (Hair Jr. et al., 2010). Using the rule of thumb, a sample size of 300 subjects was considered adequate hence used in this study.

\section{Measurements of variables and data collection}

This study developed measurement and structural models that comprised of three constructs; these are entrepreneurial orientation, competitive advantage, and SMEs' performance. The constructs were measured using various dimensions and items as shown in Table 1.

Data were collected from owners-managers of welding industry SMEs in the research area. Respondents were asked to indicate their agreement or disagreement to the questions in a structured questionnaire with 5-point Likert scale (from "strongly disagree" = 1 to "strongly agree" = 5) for entrepreneurial orientation and competitive advantage constructs. Furthermore, respondents were asked to indicate the level of change of personal wealth measures for the past 5 years to December, 2016 as a base year using a five points scale from "a lot less" = 1 to "a lot more" $=5$.

Table 1 Measurement of model variables

\begin{tabular}{|c|c|c|c|}
\hline Construct & Dimension & Number of items & Source \\
\hline \multirow[t]{5}{*}{ Entrepreneurial orientation } & Pro-activeness & Three & \multirow[t]{5}{*}{ Campos et al. (2012) } \\
\hline & Risk taking & Three & \\
\hline & Competitive aggressiveness & Two & \\
\hline & Autonomy & Three & \\
\hline & Innovativeness & Three & \\
\hline \multirow[t]{3}{*}{ Competitive advantage } & Differentiated products & Three & \multirow[t]{3}{*}{ Ramaswami et al. (2006) } \\
\hline & Market sensing & Four & \\
\hline & Market responsiveness & Five & \\
\hline \multirow{3}{*}{$\begin{array}{l}\text { SMEs' performance } \\
\text { (growth measures) }\end{array}$} & Growth in assets & One & \multirow[t]{3}{*}{ Shepherd and Wiklund (2009) } \\
\hline & Growth in sales & One & \\
\hline & $\begin{array}{l}\text { Growth in number of } \\
\text { employees }\end{array}$ & One & \\
\hline \multirow{3}{*}{$\begin{array}{l}\text { SMEs' performance } \\
\text { (personal wealth measures) }\end{array}$} & Food purchasing capability & One & \multirow[t]{3}{*}{ Eijdenberg (2016) } \\
\hline & Health care paying capability & One & \\
\hline & Shelter acquisition capability & One & \\
\hline
\end{tabular}




\section{Data analysis}

Entrepreneurial orientation and competitive advantage are second-order constructs and their dimensions are first-order constructs. To reduce model complexity, total scores for dimensions of entrepreneurial orientation and competitive advantage were computed using a statistical package for social sciences (SPSS) computer software. Total scores transformed the dimensions into observed variables while entrepreneurial orientation and competitive advantage were transformed into first order constructs. SMEs' performance measures are observed variable thus were not transformed. The transformed variables are shown in Table 2.

By the aid of analysis of moment structures (AMOS) computer software, data analysis comprised of developing measurement and structural models using confirmatory factor analysis (CFA) and structural equation modeling (SEM) techniques, respectively. Since the study used two types of SMEs' performance measures, two measurement models were developed; one for firm growth measures and the other for personal wealth measures. Likewise, two structural models were developed under the same types of performance measures.

Furthermore, sample data were bootstrapped using 200 samples to determine the direct effect of entrepreneurial orientation on competitive advantage, direct effect of competitive advantage on SMEs' performance, and indirect effect of entrepreneurial orientation on SMEs' performance through competitive advantage. Significance levels were assessed at 5\% level of significance and bias corrected (BC) 95\% confidence interval (CI) levels for each effect was assessed. The bias corrected 95\% confidence interval with 0 exclusion provides evidence for significant mediation effect (Memon, Cheah, Ramayah, Ting, \& Chuah, 2018; Cepeda, Nitzl, \& Roldán, 2018).

\section{Results}

\section{Confirmatory factor analysis}

CFA technique was used to assess the factor loadings, construct correlations, and model fit indices for the developed models based on firm growth and personal wealth measures. The subsequent sections present the measurement models.

\section{Measurement model for firm growth measures}

Differentiated products (Total DPR) dimension of competitive advantage (CA) construct had a factor loading of 0.24 which is too low $(<0.5)$ (Zainudin, 2015) hence

Table 2 Transformed model constructs

\begin{tabular}{lll}
\hline First-order construct & Observed dimensions & Abbreviation \\
\hline Entrepreneurial orientation (EO) & Pro-activeness & Total PRO \\
& Risk taking & Total RTA \\
& Competitive aggressiveness & Total CAG \\
& Autonomy & Total AUT \\
& Innovativeness & Total INN \\
Competitive advantage (CA) & Differentiated products & Total DPR \\
& Market sensing & Total MSE \\
& Market responsiveness & Total MRE \\
\hline
\end{tabular}


deleted from the model. The remaining dimensions had factor loadings greater than 0.5 hence retained for further analysis. Innovativeness (Total INN) dimension of entrepreneurial orientation construct was also deleted due to high modification index (18.227) with risk-taking (Total RTA) dimension of entrepreneurial orientation. After deletion of the two dimensions, the measurement model was found acceptable with minimum chi-square statistic (33.751, $p>0.05$ ), cmin/df ratio $<2.5$, CFI $>0.90$, and RMSEA $<0.06$ (Zainudin, 2015), and construct correlations less than 0.90 (Pallant, 2005; Tabachnick \& Fidell, 2007) (see Fig. 1).

Construct reliability (CR) and average variance extracted (AVE) values for firm growth measures were found to be 0.850 and 0.663 , respectively. AVE values higher than 0.5 and CR values higher than 0.6 indicate acceptable construct validity and reliability respectively (Zainudin, 2015).

\section{Measurement model for personal wealth measures}

Two dimensions, which are differentiated products (Total DPR) dimension of competitive advantage and innovativeness (Total INN) dimension of entrepreneurial orientation, were deleted from the model. Total DPR was deleted due to low factor loading (0.26) and Total INN was deleted due high modification index (19.072) with risk-taking (Total RTA) dimension of entrepreneurial orietation. The remaining factor loadings were found to be $\geq 0.50$. Correlations among the model constructs were less than 0.90 (Pallant, 2005; Tabachnick \& Fidell, 2007). Minimum chi-square statistic (43.188, $p<$ 0.05), $\mathrm{cmin} / \mathrm{df}<2.5, \mathrm{CFI}>0.90$, and RMSEA $<0.06$ (Zainudin, 2015) (see Fig. 2). Using personal wealth measures, SMEs' performance construct yielded $C R$ value of 0.788 and AVE value of 0.565 .

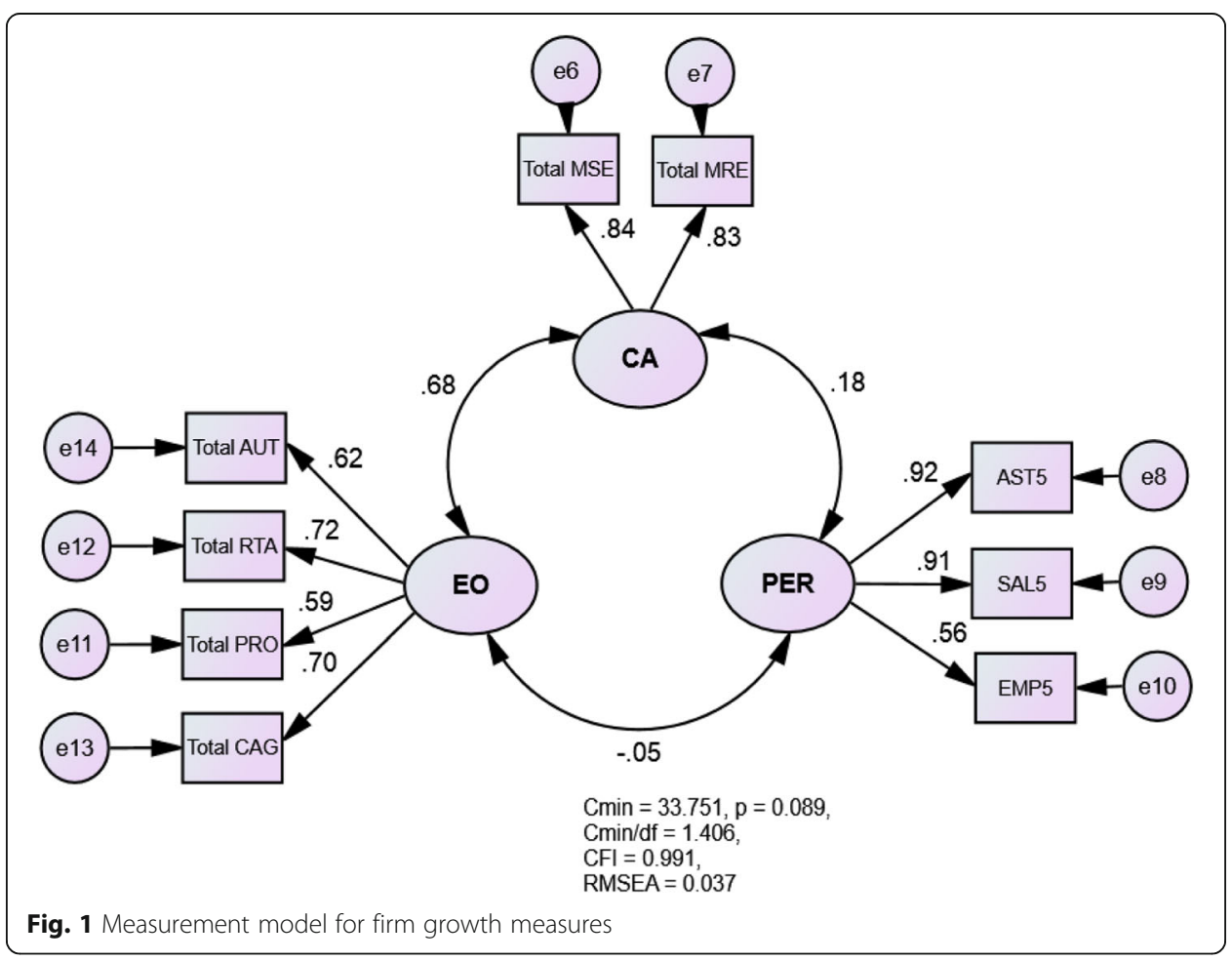




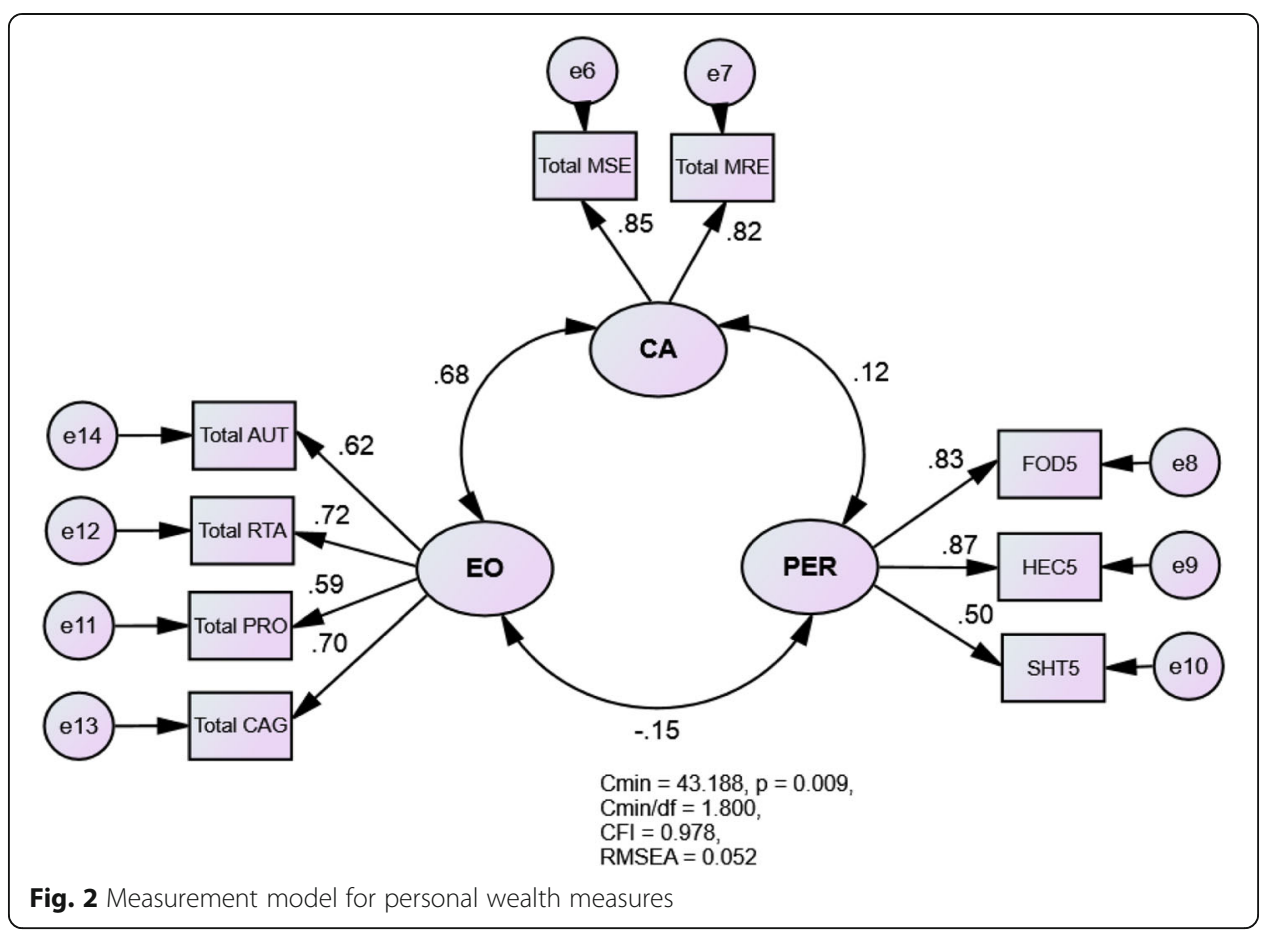

The minimum chi-square statistic was found to be significant informing that the theory implied covariance matrix is different from the observed covariance matrix. This finding is not awkward since large sample sizes more than 200 tend to produce a significant chi-square statistic (Barret, 2007). This study used a sample size of 300 subjects. Taking into consideration the effect of large sample size on statistical significance of chi-square statistic and since all other model fit indices were found to be acceptable, the model was deemed acceptable for further analysis.

\section{Hypotheses testing}

By the aid of AMOS computer software, path analysis was conducted to determine the influence of entrepreneurial orientation on competitive advantage and the influence of competitive advantage on SMEs' performance. Furthermore, bootstrapping was performed to determine the mediating effect of competitive advantage on the relationship between entrepreneurial orientation and SMEs' performance.

\section{Structural model for firm growth measures}

Results from the structural model (Fig. 3) for firm growth measures show that entrepreneurial orientation positively and significantly influences competitive advantage $(\beta=$ $0.68, p<0.001)$. Likewise, competitive advantage positively and significantly influences SMEs' performance $(\beta=0.40, p<0.001)$.

Sample bootstrapping results for direct and indirect effects for firm growth measures are summarized in Table 3. The results are three fold: firstly, the influence of entrepreneurial orientation on competitive advantage was found to be positive and significant at $5 \%$ level of significance and the bias corrected $95 \%$ confidence interval does not include 0 . Secondly, the influence of competitive advantage on SMEs' performance was found 


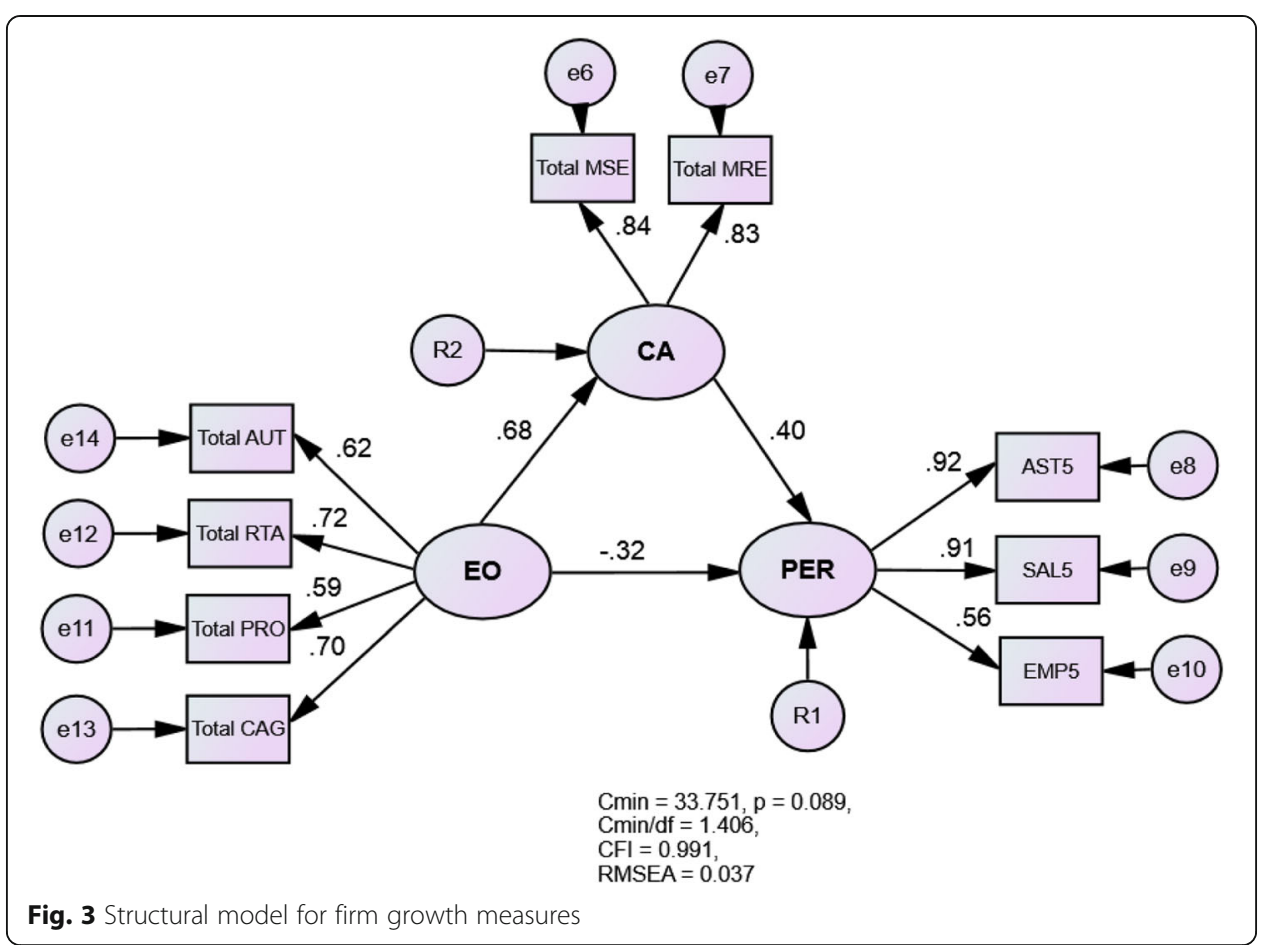

to be positive and significant at $5 \%$ level of significance and the bias corrected $95 \%$ confidence interval does not include 0. Thirdly, the indirect influence of entrepreneurial orientation on SMEs' performance through competitive advantage was found to be positive and significant at $5 \%$ level of significance and the bias corrected $95 \%$ confidence interval does not include 0 . These results provide evidence that hypotheses $\mathrm{H}_{1}$, $\mathrm{H}_{2}$, and $\mathrm{H}_{3}$ are supported by the collected data.

\section{Structural model for personal wealth measures}

Figure 4 is the structural model for personal wealth measures. Results show that entrepreneurial orientation has a positive and significant influence on competitive advantage ( $\beta=0.68, p<0.001)$ and competitive advantage has a positive and significant influence on SMEs' performance $(\beta=0.41, p<0.001)$.

Sample bootstrapping results for direct and indirect effects for personal wealth measures are shown in Table 4. The results on entrepreneurial orientation-competitive advantage, competitive advantage-SMEs' performance, and entrepreneurial orientation-competitive advantage-SMEs' performance relationships were found to be positive and significant at 5\% level of significance. In addition, the bias corrected $95 \%$

Table 3 Direct and indirect effects for firm growth measures

\begin{tabular}{|c|c|c|c|c|c|c|c|}
\hline \multirow[t]{2}{*}{ No. } & \multirow[t]{2}{*}{ Hypothesis } & \multirow{2}{*}{$\begin{array}{l}\text { Coefficient } \\
(\beta)\end{array}$} & \multirow{2}{*}{$\begin{array}{l}p \text { value } \\
\text { (2-tailed) }\end{array}$} & \multirow{2}{*}{$\begin{array}{l}\text { Significance } \\
(a=0.05)\end{array}$} & \multicolumn{2}{|c|}{ 95\% corrected bias (BC) } & \multirow[t]{2}{*}{ Decision } \\
\hline & & & & & Lower & Upper & \\
\hline $\mathrm{H}_{1}$ & $C A \leftarrow E O$ & 0.685 & 0.016 & Significant & 0.583 & 0.775 & Supported \\
\hline $\mathrm{H}_{2}$ & $P E R \leftarrow C A$ & 0.399 & 0.008 & Significant & 0.195 & 0.675 & Supported \\
\hline $\mathrm{H}_{3}$ & $\mathrm{PER} \leftarrow \mathrm{CA} \leftarrow \mathrm{EO}$ & 0.273 & 0.007 & Significant & 0.127 & 0.507 & Supported \\
\hline
\end{tabular}




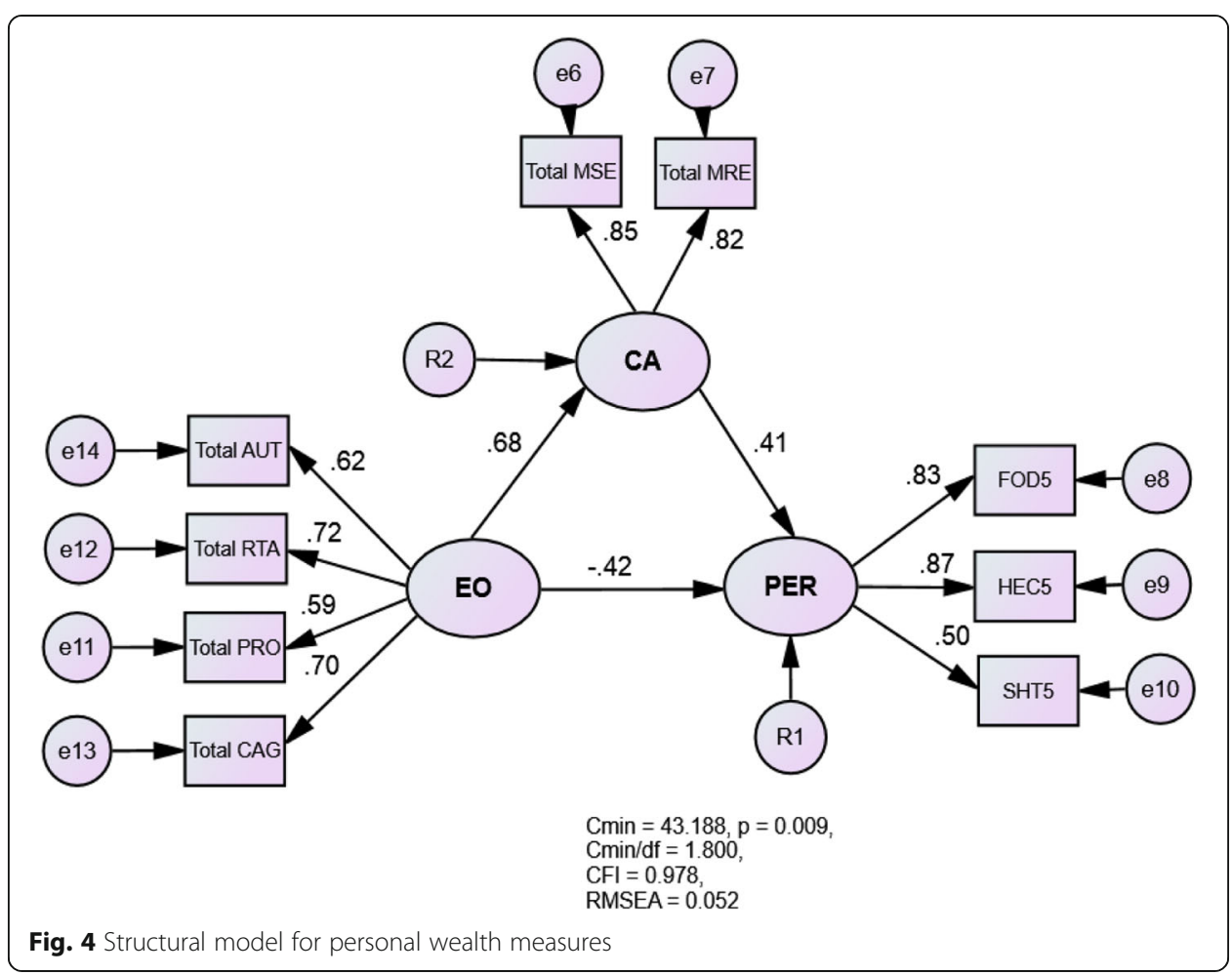

confidence intervals were all free from 0 inclusion. These results inform that hypotheses $\mathrm{H}_{1}, \mathrm{H}_{2}$, and $\mathrm{H}_{3}$ are supported by the collected data.

\section{Discussion}

This study aimed at determining the influence of entrepreneurial orientation on SMEs' performance under the mediation of competitive advantage using firm growth and personal wealth performance measures. The influences of entrepreneurial orientation on competitive advantage; competitive advantage on SMEs' performance; and the mediating effect of competitive advantage on entrepreneurial orientation and SMEs' performance relationship were determined using both firm growth and personal wealth measures. Measurement and structural models were developed using the original sample, and then bootstrapping (200 samples) was performed to determine the direct effect of entrepreneurial orientation on competitive advantage, direct effect of competitive advantage on SMEs' performance, and indirect effect of entrepreneurial orientation on SMEs' performance through competitive advantage. Findings were then compared to ascertain the extent the findings from personal wealth measures are closer or far away from findings obtained when using traditional firm growth performance measures.

Table 4 Direct and indirect effects for personal wealth measures

\begin{tabular}{|c|c|c|c|c|c|c|c|}
\hline \multirow[t]{2}{*}{ No. } & \multirow[t]{2}{*}{ Hypothesis } & \multirow{2}{*}{$\begin{array}{l}\text { Coefficient } \\
(\beta)\end{array}$} & \multirow{2}{*}{$\begin{array}{l}p \text { value } \\
\text { (2-tailed) }\end{array}$} & \multirow{2}{*}{$\begin{array}{l}\text { Significance } \\
(a=0.05)\end{array}$} & \multicolumn{2}{|c|}{$95 \% \mathrm{Cl}$ bias corrected (BC) } & \multirow[t]{2}{*}{ Decision } \\
\hline & & & & & Lower & Upper & \\
\hline $\mathrm{H}_{1}$ & $C A \leftarrow E O$ & 0.684 & 0.019 & Significant & 0.581 & 0.774 & Supported \\
\hline $\mathrm{H}_{2}$ & $\mathrm{PER} C \mathrm{CA}$ & 0.406 & 0.017 & Significant & 0.122 & 0.708 & Supported \\
\hline $\mathrm{H}_{3}$ & $\mathrm{PER} C \mathrm{CA} \leftarrow \mathrm{EO}$ & 0.278 & 0.016 & Significant & 0.088 & 0.513 & Supported \\
\hline
\end{tabular}


During measurement model development, two dimensions which are differentiated products (Total DPR) and innovativeness (Total INN) were deleted from both models (measurement models for firm growth and personal wealth measures). The former dimension was deleted from competitive advantage construct due to low factor loadings implying that the dimension poorly reflects the construct. The latter dimension was deleted from entrepreneurial orientation construct due to high modification indices with risk-taking (Total RTA) dimension; this indicates presence of redundant dimension. The deletion of both dimensions may be attributed to the fact that, to the large extent, welding industry SMEs in Tanzania do not often invent their own products, the designs of such products are dictated by instructions from customers (key informant interviews, personal communication, September 6-30, 2017). However, deletion of those dimensions did not affect the constructs' definitions because the retained dimensions reflect the same constructs just like the deleted ones do.

On the one hand, SMEs' performance was treated as a unidimensional construct reflected by firm growth measures, and on the other hand, SMEs' performance was treated as a unidimensional construct reflected by personal wealth measures. In both cases, findings show that factor loadings for all items were greater or equal to 0.50 and significant at 0.05 level of significance indicating that the items measured the same underlying construct. Further analysis on the SMEs' performance construct using firm growth measures revealed that CR value was 0.850 and AVE was 0.663. Furthermore, using personal wealth measures, SMEs' performance construct yielded CR value of 0.788 and AVE value of 0.565 . AVE values higher than 0.5 and CR values higher than 0.6 indicate acceptable construct validity and reliability, respectively (Zainudin, 2015). Based on these findings, SMEs' performance construct reflected by firm growth and personal wealth measures passed construct validity and reliability tests.

The study formulated three hypotheses to accomplish the specific objectives. Firstly, it was hypothesized that entrepreneurial orientation positively influences competitive advantage. This hypothesis was supported by both firm growth and personal wealth measures using the original sample and the bootstrapped samples. The findings comply with the resource-based view which postulates that firm's competitive advantage emanates from resources owned or controlled by the firm. Amid scanty literature, investigating the influence of entrepreneurial orientation on competitive advantage, similar findings have been reported by Mustafa et al. (2015).

Secondly, it was hypothesized that competitive advantage positively influences SMEs' performance. As in the case of first one, both firm growth and personal wealth measures supported the hypothesis using the original sample and the bootstrapped samples. The findings confirm the resource-based view which postulates that competitive advantage promotes firm performance. These findings are in line with the findings reported in past studies (see Ismail et al., 2010; Majeed, 2011; Muafi \& Roostika, 2014; Wijetunge, 2016; Zhou et al., 2009).

Thirdly, the study hypothesized that competitive advantage mediates the relationship between entrepreneurial orientation and SMEs' performance. Findings from bootstrapping data supported the proposition for both firm growth and personal wealth measures. The findings are in line with the resource-based view which postulates that competitive advantage and firm performance emanate from resources owned or controlled by the firm. Such findings have also been reported by Mustafa et al. (2015). 
Although it was not possible to compare the findings of this study with findings from past studies using personal wealth performance measures due to lack of literature on the subject, it is interesting to note that the coefficient values for all hypotheses using firm growth measures are very close to the coefficient values for all hypotheses using personal wealth measures (see Table 3 and Table 4). Thus, it is evident that the proposition of Eijdenberg (2016) that personal wealth measures can be used in least developed countries to measure SMEs' performance has been supported in this study.

\section{Conclusion, implication, and recommendations}

\section{Conclusion}

Based on the findings and discussion of the same, it is evident that firm growth and personal wealth performance measures produced similar findings. Thus, this study concludes that when both firm growth and personal wealth performance measures were used: first, entrepreneurial orientation positively and significantly influenced competitive advantage; second, competitive advantage positively and significantly influenced SMEs' performance; and third, competitive advantage mediated the relationship between entrepreneurial orientation and SMEs' performance. Although firm growth measures have been developed in western world, this study has revealed that the measures are still applicable in least developed countries. Despite the novelty of personal wealth performance measures, it has been demonstrated that the measures are as good as the firm growth measures.

\section{Contribution of the study}

Guided by the resource-based view, this study determined the influence of entrepreneurial orientation on SMEs' performance under the mediation of competitive advantage. Firm growth and personal wealth measures were used as indicators of SMEs' performance. This study has contributed to the existing literature by providing empirical evidence on the extent entrepreneurial orientation influences SMEs' performance under the mediation of competitive advantage using personal wealth as measures of SMEs' performance which are food purchasing, health care paying, and shelter acquisition capabilities. The need to use these performance measures in Tanzania and other least developed countries was raised in the work of Eijdenberg (2016). However, since then, to the best knowledge of the authors, no study has attempted to obtain empirical evidence on their suitability as SMEs' performance measures in Tanzania. Use of both firm growth and personal wealth performance measures distinguishes this study from past studies.

\section{Implication of the findings}

Entrepreneurial orientation has been used as a firm resource in form of processes (Barney, 1991), this study has proved that the influence of entrepreneurial orientation on SMEs' performance is mediated by competitive advantage. The findings of this study inform that the resource-based view is suitable to explain not only physical resources but also intangible resources such as entrepreneurial orientation. In modern business environment, firm performance is much driven by intangible resources than physical resources (Connor, 2002). Therefore, firm owners-managers ought to invest not only in physical resources but also in intangible resources in order to create competitive advantage and eventually promote SMEs' performance. 
In practice, given the differences in paradigms in which entrepreneurs in western world and least developed countries operate; whereby the former cohort is motivated by opportunities, and the latter is motivated by necessities (Eijdenberg, 2016), time has come for researchers and other stakeholders in least developed countries to embrace use of both personal wealth and traditional firm growth performance measures to capture the whole picture of SMEs' performance. After investment of resources in a firm for some time, firm owners-managers tend to stop investing anymore; hence, use of firm growth measures such as growth in assets, sales, and number of employees may indicate poor SMEs' performance while much of earnings from SMEs are spent to sustain the livelihood of entrepreneurs and the associated accumulation of wealth. Since this wealth is obtained from the enterprises owned and managed by entrepreneurs, although there may not be significant firm growth over a certain measurement period, it may not be right to claim poor performance of such SMEs while the lifestyle of entrepreneurs keeps changing positively. This reality prompts the need to use both personal wealth and traditional firm growth performance measures when assessing SMEs' performance in least developed countries. In this regard, the findings from this study are expected to kindle debates on the suitability of personal wealth as SMEs' performance measures. The findings are also expected to stand as a stepping stone in future studies.

\section{Limitation of the study}

The data for this research were collected from the welding industry in Tanzania; thus, the findings cannot be generalized beyond the welding industry. Furthermore, it is well known that competitive advantage and SMEs' performance can be measured using various dimensions. In this study, measurement of competitive advantage is limited to three dimensions which are differentiated products, market sensing, and market responsiveness. Likewise, measurement of SMEs' performance is limited to firm growth measures (assets, sales, and employees) and personal wealth measures (food purchasing, health care paying, and shelter acquisition capabilities).

\section{Recommendations}

This study has revealed the interconnection between the entrepreneurs' earnings from enterprises and their lifestyle as related to SMEs' performance. Firm growth measures are not the only indicators of SMEs' performance. Therefore, it is hereby recommended that measurement of SMEs' performance whether in research works or practice should not be confined only to firm growth measures but also to personal wealth measures. Concurrent use of both measures in least developed countries will appropriately portray the SMEs' performance than use of firm growth only.

This study has attempted to investigate the influence of entrepreneurial orientation on SMEs' performance under the mediation of competitive advantage. The findings provide promising avenues to investigate the influence of more constructs such as learning orientation on SMEs' performance under the mediation of competitive advantage using the same firm growth and personal wealth performance measures. Such studies will establish whether the findings of this study are specific to entrepreneurial orientation construct or applicable to other constructs. 


\section{Abbreviations}

AMOS: Analysis of moment structures; AST5: Assets growth for the past 5 years; AVE: Average variance extracted; BC: Bias corrected; CA: Competitive advantage; CFA: Confirmatory factor analysis; Cl: Confidence interval; Cmin: Minimum chi-square statistic; CR: Construct reliability; df: Degrees of freedom; EMP5: Growth in the number of employees for the past 5 years; EO: Entrepreneurial orientation construct; FOD5: Food purchasing capacity for past 5 years; HEC5: Health care paying capacity for past 5 years; MI: Modification Index; SAL5: Sales growth for the past 5 years; PER: Performance construct; SEM: Structural equation modeling; SHT5: Shelter acquisition capacity for past 5 years; SMEs: Small and medium enterprises; SPSS: Statistical Package for Social Sciences; Total AUT: Total score for autonomy construct; Total CAG: Total score for competitive aggressiveness construct; Total INN: Total score for innovation construct; Total MRE: Total score for market responsiveness; Total MSE: Total score for market sensing; Total PRO: Total score for pro-activeness construct; Total RTA: Total score for risk-taking construct

\section{Acknowledgements}

The authors are indebted to the anonymous reviewers whose comments improved the contents of this paper.

\section{Authors' contributions}

KK designed and conducted the study under the supervision of NI. Specifically, KK designed a research proposal, collected and analyzed the data, and prepared a draft version of this paper. In all stages, NI read the work and accordingly raised some comments which were incorporated to address the observed weaknesses in this study. Finally, all authors approved the submission of the paper to the Journal of Innovation and Entrepreneurship to be considered for publication. All authors read and approved the final manuscript.

\section{Authors' information}

Kibeshi Kiyabo (MSc) is a PhD candidate at Mzumbe University in Tanzania. Dr. Nsubili Isaga (PhD) is a Senior lecturer at School of Business, Mzumbe University, Tanzania.

\section{Funding}

The study received no funds from any individual or organization other than the authors.

\section{Availability of data and materials}

Datasets for this study are available and the same can be obtained from a corresponding author on reasonable request.

\section{Competing interests}

The authors declare that they have no competing interests.

Received: 6 March 2020 Accepted: 30 June 2020

Published online: 09 July 2020

\section{References}

Amin, M. (2015). The effect of entrepreneurship orientation and learning orientation on SMEs' performance: an SEM - PLS approach. Journal of International Business and Entrepreneurship Development, 8(3), 215-230.

Amin, M., Thurasamy, R., Mohamad, A., Aznur, A., \& Kaswuri, H. (2016). The effect of market orientation as a mediating variable in the relationship between entrepreneurial orientation and SMEs performance. Nankai Business Review International, 7(1), 39-59.

Barney, J. (1991). Firm resources and sustained competitive advantage. Journal of Management, 17(1), 99-120.

Barret, P. (2007). Structural equation modelling: adjudging model fit. Personality and Individual Differences, 42, 815-824.

Campos, H. M., Nuno de la Parra, J. P., \& Parellada, F. S. (2012). The entrepreneurial orientation-dominant logic-performance relationship in new ventures: An exploratory quantitative study. BAR, Rio de Janeiro, 9(4), 60-77.

Campos, H. M., \& Valenzuela, F. A. A. (2013). The relationship between entrepreneurial orientation, time orientation and small business performance: an evidence from Mexico. Revista da Micro e Pequena Empresa, Campo Limpo Paulista, 7(1), 48-63.

Cepeda, G., Nitzl, C., \& Roldán, J. L. (2018). Mediation analyses in partial least squares structural equation modeling: guidelines and empirical examples. In H. Latan \& R. Noonan (Eds.), Partial least squares structural equation modeling: basic concepts, methodological issues and applications. Heidelberg: Springer.

Chenuos, N. K., \& Maru, L. C. (2015). Entrepreneurial orientation and firm performance: Evidence from small and microenterprises in Kenya. European Journal of Business and Management., 7(27), 187-196.

Chong, H. G. (2008). Measuring performance of small-and-medium sized enterprises: the grounded theory approach. Journal of Business and Public Affairs, 2(1), 1-10.

Connor, T. (2002). The resource-based view of strategy and its value to practising managers. Strategic Change, 11, 307-316.

Covin, J. G., Wales, W., \& J. (2019). Crafting high-impact entrepreneurial orientation research: Some suggested guidelines. Entrepreneurship Theory and Practice, 43(1), 3-18.

Eijdenberg, E. L. (2016). Does one size fit all? A look at entrepreneurial motivation and entrepreneurial orientation in the informal economy of Tanzania. International Journal of Entrepreneurial Behavior \& Research, 22(6), 1-31.

Fatoki, O. (2012). The impact of entrepreneurial orientation on access to debt finance and performance of small and medium enterprises in South Africa. Journal of Social Sciences, 32(2), 121-131.

Gupta, V. K. (2015). Construction of entrepreneurial orientation: dispute, demand, and dare. New England Journal of Entrepreneurship, 18(1), 87-89.

Hair Jr., J. F., Black, W. C., Babin, B. J., \& Anderson, R. E. (2010). Multivariate Data Analysis: Global Perspective. New Jersey: Pearson Prentice Hall.

Ismail, A. I., Rose, R. C., Abdullah, H., \& Uli, J. (2010). The relationship between organisational competitive advantage and performance moderated by the age and size of firms. Asian Academy of Management Journal, 15(2), 157-173. 
Kotane, I., \& Kuzimina-Merlino, I. (2017). Analysis of small and medium sized enterprises' business performance evaluation practice at transportation and storage services sector in Latvia. Procedia Engineering, 178, 182-191.

Lumpkin, G. T., \& Dess, G. G. (1996). Clarifying the entrepreneurial orientation construct and linking it to performance. Academy of Management Review, 21(1), 135-172.

Mahmood, R., \& Hanafi, N. (2013). Entrepreneurial orientation and business performance of women-owned small and medium enterprises in Malaysia: Competitive advantage as a mediator. International Journal of Business and Social Science, 4(1), 82-90.

Majeed, S. (2011). The Impact of Competitive Advantage on Organizational Performance. European Journal of Business and Management, 3(4), 191-196.

Mata, B. A. K., \& Aliyu, M. S. (2014). The relationship between some determinants of SME performance in Nigeria: A qualitative approach. European Journal of Business and Management, 6(2), 107-114.

Memon, M. A., Cheah, J., Ramayah, T., Ting, H., \& Chuah, F. (2018). Mediation analysis issues and recommendations. Journal of Applied Structural Equation Modeling, 2(1), 1-9.

Muafi, P., \& Roostika, R. (2014). Organizational performance and competitive advantage determinants of creative SMEs. European Journal of Economics and Management, 1(2), 7-25.

Mustafa, H., Rehman, K. U., Zaidi, S. A. R., \& lqbal, F. (2015). Studying the phenomenon of competitive advantage and differentiation: Market and entrepreneurial orientation perspective. Journal of Business and Management Sciences, 3(4), $111-117$.

Pallant, J. (2005). SPSS survival manual: a step quide to data analysis using SPSS for Windows (Version 12). Sydney: Allen \& Unwin.

Ramaswami, S. N., Srivastava, R. and Bhargava, M. (2006). Market-based assets and capabilities, business processes, and financial performance. Emory University.

Rauch, A., Wiklund, J., Lumpkin, G. T., \& Frese, M. (2009). Entrepreneurial orientation and business performance: An assessment of past research and suggestions for the future. Entrepreneurship Theory and Practice, 33(3), 761-787.

Shepherd, D., \& Wiklund, J. (2009). Are we comparing apples with apples or apples with oranges? Appropriateness of knowledge accumulation across growth studies. Entrepreneurship Theory and Practice, 33(1), 105-123.

Tabachnick, B. G., \& Fidell, L. S. (2007). Using multivariate statistics. New York: Pearson Education, Inc.

Wijetunge, W. A. D. S. (2016). Service quality, competitive advantage and business performance in service providing SMEs in Sri Lanka. International Journal of Scientific and Research Publications, 6(7), 720-728.

Yeni, Y. H. (2015). The influence of entrepreneurial orientation and learning orientation on firm performance of MSMEs in west Sumatra. Paper presented at the Australasian conference on business and social sciences. Sydney.

Zainudin, A. (2015). SEM Made Simple: A gentle approach to learning structural equation modeling. Bangi: MPWS Rich Publication.

Zehir, C., Can, E., \& Karaboga, T. (2015). Linking entrepreneurial orientation to firm performance: The role of differentiation strategy and innovation performance. Procedia - Social and Behavioural Sciences, 210, 358-367.

Zhou, K. Z., Brown, J. R., \& Dev, C. S. (2009). Market orientation, competitive advantage, and performance: A demand-based perspective. Journal of Business Research, 62(11), 1063-1070.

Zulkifli, R. M., \& Rosli, M. M. (2013). Entrepreneurial orientation and business success of Malay entrepreneurs: religiosity as moderator. International Journal of Humanities and Social Science, 3(10), 264-275.

\section{Publisher's Note}

Springer Nature remains neutral with regard to jurisdictional claims in published maps and institutional affiliations.

\section{Submit your manuscript to a SpringerOpen ${ }^{\circ}$ journal and benefit from:}

- Convenient online submission

- Rigorous peer review

- Open access: articles freely available online

- High visibility within the field

Retaining the copyright to your article

Submit your next manuscript at $\boldsymbol{\sim}$ springeropen.com 